\title{
Sleep-wake disorders persist 18 months after traumatic brain injury but remain underrecognized
}

Lukas L. Imbach, MD* Fabian Büchele, MD* Philipp O. Valko, MD Tongzhou Li Angelina Maric, MSc John F. Stover, MD Claudio L. Bassetti, MD Ladislav Mica, MD Esther Werth, PhD Christian R. Baumann, MD

Correspondence to Dr. Imbach: lukas.imbach@usz.ch

\section{ABSTRACT}

Objective: This study is a prospective, controlled clinical and electrophysiologic trial examining the chronic course of posttraumatic sleep-wake disturbances (SWD).

Methods: We screened 140 patients with acute, first-ever traumatic brain injury of any severity and included 60 patients for prospective follow-up examinations. Patients with prior brain trauma, other neurologic or systemic disease, drug abuse, or psychiatric comorbidities were excluded. Eighteen months after trauma, we performed detailed sleep assessment in 31 participants. As a control group, we enrolled healthy individuals without prior brain trauma matched for age, sex, and sleep satiation.

Results: In the chronic state after traumatic brain injury, sleep need per 24 hours was persistently increased in trauma patients ( $8.1 \pm 0.5$ hours) as compared to healthy controls ( $7.1 \pm 0.7$ hours). The prevalence of chronic objective excessive daytime sleepiness was $67 \%$ in patients with brain trauma compared to $19 \%$ in controls. Patients significantly underestimated excessive daytime sleepiness and sleep need, emphasizing the unreliability of self-assessments on SWD in trauma patients.

Conclusions: This study provides prospective, controlled, and objective evidence for chronic persistence of posttraumatic SWD, which remain underestimated by patients. These results have clinical and medicolegal implications given that SWD can exacerbate other outcomes of traumatic brain injury, impair quality of life, and are associated with public safety hazards. Neurology ${ }^{\circledast}$ 2016;86:1945-1949

\section{GLOSSARY}

EDS = excessive daytime sleepiness; $\mathbf{I C H}=$ intracranial hemorrhage; $\mathbf{S W D}=$ sleep-wake disturbances; $\mathbf{T B I}=$ traumatic brain injury.

After a long period of neglect, there is now accumulating evidence that posttraumatic sleepwake disturbances (SWD) belong to the most prevalent sleep-wake disorders in Western societies. ${ }^{1-6}$ Although there is a lack of high-quality epidemiologic data on traumatic brain injury (TBI), there is evidence that the worldwide incidence of TBI is rising: for instance, 1.7 million people sustain a TBI each year in the United States. ${ }^{7}$ Given that a majority of patients experience SWD after TBI of any severity, ${ }^{1,8}$ the incidence of newly developed posttraumatic SWD is rising as well. An important factor contributing to the widespread lack of insight into this problem is the observation that patients with TBI tend to markedly underestimate their posttraumatic sleep-wake problems, in particular symptoms of increased sleep pressure and sleep need, also referred to as pleiosomnia. ${ }^{1}$ Still, objective and prospective data on posttraumatic sleep-wake behavior are only available within the first 6 months after trauma. ${ }^{1,8}$ From a clinical and medicolegal point of view, it is therefore critical to have further insights into the long-time course of posttraumatic sleep disturbances. Therefore, we extended a previous prospective study ${ }^{1}$ to assess chronic posttraumatic SWD 18 months after mild, moderate, and severe TBI.

\footnotetext{
*These authors contributed equally to this work.

From the Departments of Neurology (L.L.I., F.B., P.O.V., T.L., A.M., E.W., C.R.B.) and Traumatology (J.F.S., L.M.), University Hospital Zurich; and Department of Neurology (C.L.B.), Inselspital Bern, Switzerland.

Go to Neurology.org for full disclosures. Funding information and disclosures deemed relevant by the authors, if any, are provided at the end of the article.
} 
Table Demographic data, clinical characteristics, and sleep measures for patients with TBI and controls

\begin{tabular}{|c|c|c|c|}
\hline & Controls & 18 mo post-TBI & p Value ${ }^{a}$ \\
\hline \multicolumn{4}{|l|}{ Clinical characteristics } \\
\hline Age, y & $36.5 \pm 13.1$ & $33.2 \pm 13.9$ & NS \\
\hline Sex, M/F & $31 / 11$ & $20 / 11$ & NS \\
\hline Difference WDs/WEs ${ }^{b}$ & $0.42 \pm 0.9$ & $0.31 \pm 1.8$ & NS \\
\hline $\mathrm{ICH}+/ / \mathrm{CH}-$ & - & $21 / 10$ & NA \\
\hline $\begin{array}{l}\text { ICH location, intral } \\
\text { extra/both }\end{array}$ & - & $4 / 6 / 11$ & NS \\
\hline ICH no., single/multiple ${ }^{d}$ & - & $6 / 15$ & NS \\
\hline $\mathrm{ICH}$ size, small/large ${ }^{e}$ & - & $9 / 12$ & NS \\
\hline $\begin{array}{l}\text { ICH side, unilateral/ } \\
\text { bilateral }\end{array}$ & - & $10 / 11$ & NS \\
\hline $\begin{array}{l}\text { TBI severity, mild/ } \\
\text { moderate/severe }\end{array}$ & - & $21 / 2 / 8$ & NS \\
\hline \multicolumn{4}{|l|}{$\begin{array}{l}\text { Polysomnography } \\
\text { measures }^{f}\end{array}$} \\
\hline Wake, \% & $11.4 \pm 1.6$ & $6.6 \pm 1.1$ & NS \\
\hline NREM1, \% & $9.1 \pm 0.7$ & $10.1 \pm 0.9$ & NS \\
\hline NREM2, \% & $41.2 \pm 1.2$ & $43.1 \pm 1.1$ & NS \\
\hline NREM3, \% & $20.2 \pm 1.2$ & $21.3 \pm 1.2$ & NS \\
\hline REM, \% & $18.1 \pm 0.9$ & $18.9 \pm 0.9$ & NS \\
\hline Arousal index & $7.7 \pm 0.8$ & $9.2 \pm 0.9$ & NS \\
\hline PLMS index & $1.3 \pm 0.8$ & $4.4 \pm 1.2$ & NS \\
\hline AHI & $3.2 \pm 1.0$ & $3.0 \pm 0.9$ & NS \\
\hline $\begin{array}{l}\text { Total sleep time } \\
\text { (PSG), min }\end{array}$ & $392 \pm 11$ & $432 \pm 6$ & $<0.005$ \\
\hline $\begin{array}{l}\text { Total delta power } \\
\text { (SWS), } \mu \mathrm{V}^{2}\end{array}$ & $512 \pm 60$ & $553 \pm 61$ & NS \\
\hline Sleep latency (PSG), min & $32 \pm 7$ & $18 \pm 2$ & NS \\
\hline $\begin{array}{l}\text { Sleep fragmentation } \\
\text { index }\end{array}$ & $0.14 \pm 0.04$ & $0.14 \pm 0.04$ & NS \\
\hline \multicolumn{4}{|l|}{$\begin{array}{l}\text { Objective sleepiness } \\
\text { (MSLT) }\end{array}$} \\
\hline MSL, min & $12.1 \pm 0.7$ & $7.0 \pm 0.7$ & $<0.00005$ \\
\hline MSL <8 min, $\mathrm{n}(\%)$ & 8/42 (19) & 21/31 (67) & $<0.00005$ \\
\hline SOREM $\geq 2^{\mathrm{g}}$ & $4 / 42$ & $3 / 31$ & NS \\
\hline \multicolumn{4}{|l|}{ Actigraphy ${ }^{h}$} \\
\hline Sleep time/24 h (total) & $7.1 \pm 0.7$ & $8.1 \pm 0.5$ & $<0.00005$ \\
\hline $\begin{array}{l}\text { Sleep time/24 h } \\
\text { (daytime) }\end{array}$ & $0.2 \pm 0.2$ & $0.5 \pm 0.2$ & NS \\
\hline \multicolumn{4}{|l|}{$\begin{array}{l}\text { Subjective sleep } \\
\text { measures }\end{array}$} \\
\hline ESS & $5.6 \pm 0.5$ & $4.9 \pm 0.5$ & NS \\
\hline FSS & $2.7 \pm 0.2$ & $2.8 \pm 0.2$ & NS \\
\hline ESS $\geq 10, n(\%)$ & $7 / 42(16)$ & 4/31 (12) & NS \\
\hline $\begin{array}{l}\text { Sleep time } / 24 \mathrm{~h} \\
\text { (sleep log), h }\end{array}$ & $7.3 \pm 1.1$ & $7.6 \pm 0.7$ & NS \\
\hline \multicolumn{4}{|l|}{ Employment situation } \\
\hline Employment level, \% & $78(6 \mathrm{mo})$ & 89 (18 mo) & NS \\
\hline Part-time/full-time & $7 / 19$ (6 mo) & $25 / 4$ (18 mo) & NS \\
\hline
\end{tabular}

Continued
METHODS Patients and study protocol. Between 2009 and 2012, we screened 140 patients with acute, first-ever TBI and included 60 patients. ${ }^{1}$ Patients with prior TBI, sleep-wake disorders, other neurologic or systemic disease, drug or alcohol abuse, or psychiatric comorbidities were excluded. We categorized the severity of TBI using the initial Glasgow Coma Scale (13-15: mild; 9-12: moderate; 3-8: severe) and performed CT scans within the first 4 hours after TBI.

As a control group, we enrolled 42 healthy individuals matched for age, sex, and sleep satiation (table). Patients with mean sleep latencies between 5 and 8 minutes in multiple sleep latency tests were accepted for inclusion as controls if no subjective excessive daytime sleepiness (EDS) was indicated by the Epworth Sleepiness Scale. Eighteen months after TBI, 31 patients were available for follow-up examinations. Eleven participants were lost to follow-up for various reasons (work: $\mathrm{n}=2$; moved to a foreign country: $\mathrm{n}=1$; no reason given: $\mathrm{n}=8$ ). We screened for changes in sleep habits, work situation, daytime vigilance, and fatigue by structured interviews. Wrist actigraphy over 2 weeks was used to assess sleep need per 24 hours as described before. ${ }^{9}$ We performed overnight video-polysomnography from 11 PM to $7 \mathrm{AM}$ and calculated delta power in slow-wave sleep and sleep fragmentation using customized scripts in MATLAB (2009; The MathWorks Inc., Natick, MA) as described before. ${ }^{1}$ Objective EDS was assessed by standardized multiple sleep latency tests and diagnosed when mean sleep latencies were below 8 minutes. ${ }^{10}$

Standard protocol approvals, registrations, and patient consents. Written informed consent for study participation was obtained from all participants. For unconscious patients or patients incapable of decision-making, written informed consent for study inclusion was provided by family members. The study protocol was approved by the local ethics committee (Kantonale Ethikkommission Zürich).

Statistical analysis. We compared patients with TBI and controls with unpaired 2-sided $t$ tests and data from patients with TBI at different time points with 1-way analysis of variance. We used $\chi^{2}$ statistics to compare nominal data and McNemar statistics to compare the diagnostic value of subjective vs objective sleepiness. We performed bivariate correlation analysis to correlate trauma severity (Glasgow Coma Scale) with sleep outcome.

RESULTS Increased sleep need. Eighteen months after TBI, actigraphy revealed prolonged sleep duration per 24 hours in patients with TBI $(8.1 \pm$ 0.5 hours) as compared to healthy controls (7.1 \pm 0.7 hours, $p<0.005$ ). Average sleep duration did not change between 6 and 18 months after TBI (figure 1A). Similarly, total sleep time in nocturnal polysomnography was higher in patients with $\mathrm{TBI}$ as compared to controls (table). Sleep microstructure (delta power, sleep fragmentation) and global sleep architecture (distribution of sleep stages) were normal in patients with TBI (table). Duration of daytime sleep by actigraphy was not increased in patients with TBI as compared to controls (table).

Objective and subjective sleepiness. Multiple sleep latency tests revealed markedly diminished sleep latencies 18 months after TBI (table, figure 1B). The prevalence of chronic objective EDS was $67 \%$ 


\begin{tabular}{|llll|}
\hline Table Continued & & & \\
& Controls & 18 mo post-TBI & $p$ Value \\
Correlation analysis & & & \\
Total sleep time vs GCS & - & $r=0.17^{\mathrm{a}}$ & NS \\
MSL vs GCS & - & $r=-0.08^{\mathrm{a}}$ & NS \\
\hline
\end{tabular}

Abbreviations: $\mathrm{AHI}=$ apnea-hypopnea index; ESS = Epworth Sleepiness Scale; FSS = Fatigue Severity Scale; GCS = Glasgow Coma Scale; $\mathrm{ICH}=$ intracranial hemorrhage; $M S L=$ multiple sleep latency; MSLT = multiple sleep latency tests; NA = not applicable; NREM = non-REM; NS = not significant; PLMS = periodic limb movements during sleep; PSG = polysomnography; SOREM = sleep onset REM; SWS = slow wave sleep (1-4 Hz); $\mathrm{TBI}=$ traumatic brain injury; $\mathrm{WD}=$ weekday; $\mathrm{WE}=$ weekend.

a Statistic measures: The $p$ values are given for comparison of controls vs patients with TBI (statistical comparison: $t$ tests between groups, $\chi^{2}$ statistics for nominal data, and analysis of variance for subgroup analyses within patients with TBI). Pearson $r$ values are shown for bivariate correlations.

${ }^{\mathrm{b}}$ Difference WDs/WEs = difference of daily hours of sleep between WDs and WEs.

${ }^{\mathrm{c}} \mathrm{ICH}$ location = intracerebral (intra), extracerebral (extra), or both.

${ }^{\mathrm{d}} \mathrm{ICH}$ no. = single, solitary $\mathrm{ICH}$; multiple, 2 or more $\mathrm{ICH}$.

${ }^{\mathrm{e}} \mathrm{ICH}$ size $=$ small, $\mathrm{ICH}$ diameter $<2 \mathrm{~mm}$; large, $\mathrm{ICH}$ diameter $>2 \mathrm{~mm}$.

${ }^{f}$ Relative amounts of sleep stages are given in percentage of total time in bed for NREM sleep stage 1 (NREM1), NREM2, NREM3, REM sleep, and wakefulness.

g SOREM $\geq 2$ = no. of patients with 2 or more SOREM in MSLT.

${ }^{\mathrm{h}}$ Sleep time per 24 hours (actigraphy) = total time asleep as measured by 2-week actigraphy recordings in 24 hours (total) and during daytime naps only (daytime); sleep time per 24 hours (sleep log) = time asleep per 24 hours as assessed by sleep logs.

in patients with TBI compared to $19 \%$ in controls $(p<0.0005$, figure 1C). Again, prevalence and severity of EDS were similar 6 and 18 months after TBI (figure 1, B and C).

In contrast, subjective measurements of EDS revealed normal findings (figure 1C, table). Comparing subjective and objective measures of sleepiness, we found significant differences only in patients with TBI, indicating persistent misperception of SWD after TBI. Similarly, self-reported sleep logs failed to reveal a difference between patients with TBI and controls (table). We found no comorbidities that might have contributed to sleepiness after TBI (table). Furthermore, neither actigraphy nor questionnaires showed evidence for insomnia after TBI.

Clinical predictors of posttraumatic SWD. The presence of intracranial hemorrhage ( $\mathrm{ICH}$ ) was a risk factor for pleiosomnia 6 months after TBI. ${ }^{1}$ Eighteen months after TBI, this association was lost (table). Although pleiosomnia persisted on the same level, the variance within the study cohort was strikingly reduced and pleiosomnia was independent from clinical trauma characteristics (figure 2, table). Furthermore, subgroup analysis among patients with ICH did not reveal any significant difference regarding size, side, location, or number of hemorrhages upon initial CT scan (table). Trauma severity (as measured by the Glasgow Coma Scale or ICH) did not correlate with objective EDS, neither 6 nor 18 months after TBI (table).

DISCUSSION In agreement with previous prospective studies $^{1,2}$ and with other thorough, but mainly retrospective or uncontrolled studies, ${ }^{3-5}$ we now provide longterm, prospective, controlled, and electrophysiologic evidence that sleepiness and pleiosomnia remain

Figure 1 Objective and subjective sleepiness in patients with TBI and healthy controls
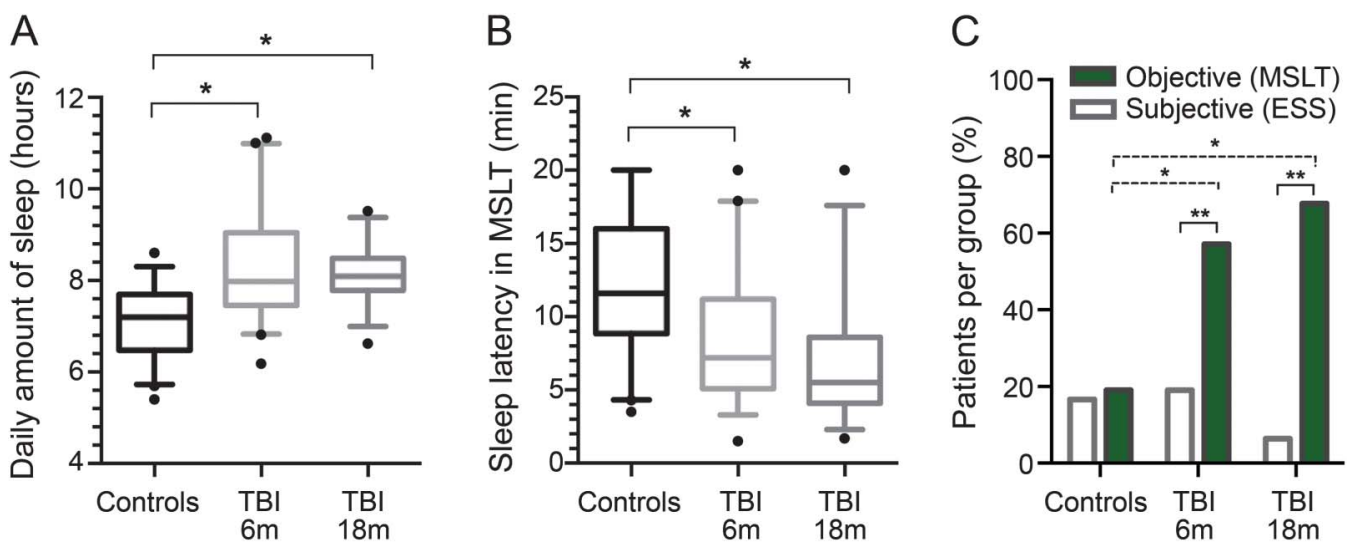

(A) Daily hours of sleep as measured by continuous actigraphy over 2 weeks, showing persistent increase of 1.0 hours in total amount of sleep per 24 hours in patients 18 months after TBI as compared to the control group. No change was observed comparing patients 6 months and 18 months after TBI (*p < 0.005). (B) Mean sleep latencies on MSLT in patients 18 months after TBI were significantly lower than in healthy controls and unchanged as compared to the 6-month follow-up $(* p<0.005)$. (C) Comparison of subjective EDS (ESS score $\geq 10$, open bars) and objective EDS (MSLT $<8$ minutes, filled bars). In healthy controls, no difference between subjective and objective measures was found. Patients with TBI showed a persistent underestimation of sleep-wake disturbances when assessed subjectively 6 months and 18 months after TBI (McNemar objective vs subjective EDS: $p>0.99$ in controls and $* * p<0.0005$ in patients with TBI). The prevalence of chronic objective EDS was $67 \%$ in patients with TBI as compared to $19 \%$ in controls $(* p<0.005)$. Box plots indicate medians (horizontal line), upper and lower quartiles (box), and extrema (whiskers); outliers are shown as black dots. EDS = excessive daytime sleepiness; ESS = Epworth Sleepiness Scale; $m=$ month; MSLT = multiple sleep latency tests; TBI = traumatic brain injury. 
Figure 2 Time course of posttraumatic pleiosomnia in patients 6 and 18 months after TBI
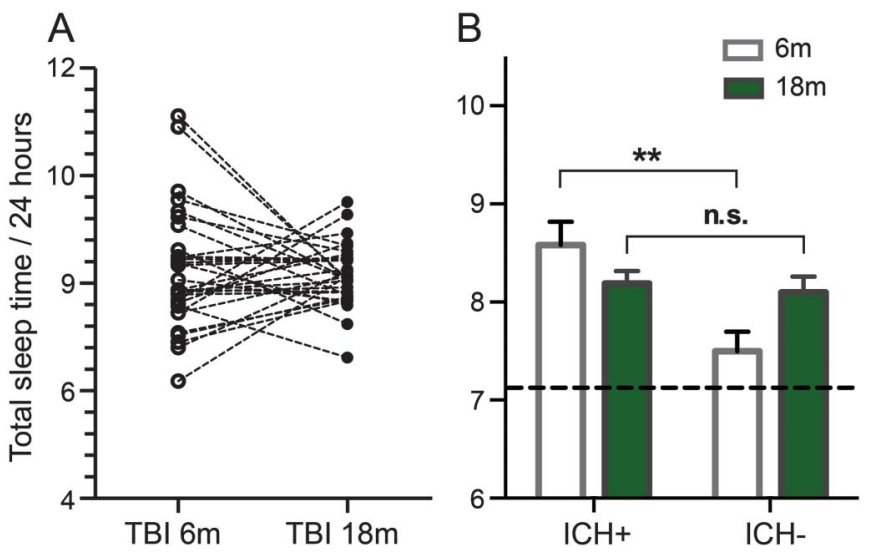

(A) Total sleep time per 24 hours in 31 patients with TBI 6 months (open circles) and 18 months (filled circles) after traumatic brain injury. Total variance of pleiosomnia was higher 6 months after TBI as compared to the follow-up examination after 18 months. Dashed lines connect values of the same patient. (B) Patients with $\mathrm{ICH}(\mathrm{ICH}+)$ showed improvement of pleiosomnia 18 months (filled bars) as compared to 6 months after TBI (open bars). Six months after TBI, patients with and without ICH differed significantly (open bars), but after 18 months, no difference was observed between the groups (filled bars). Mean sleep time per 24 hours in controls is indicated by a horizontal dashed line. $* * p<0.05 . \mathrm{ICH}=$ intracranial hemorrhage; $\mathrm{m}=$ month; $\mathrm{n} . \mathrm{s}$. = not significant; $\mathrm{TBI}=$ traumatic brain injury.

a significant problem not only in the first months after TBI, but also in the long run. As we assessed the same study cohort at different time points, our data suggest that posttraumatic SWD transform into a chronic state of disease in a majority of patients with TBI.

TBI is considered a "silent epidemic," as today's societies are largely unaware of the magnitude of this problem despite its high and continuously increasing incidence. ${ }^{7,11}$ This applies in particular to posttraumatic SWD because they are widely neglected by the affected patients themselves. In this line, this trial confirms previous reports of sleep misperception after TBI and also in the chronic state after TBI. ${ }^{1,12}$ From a medicolegal point of view, EDS is associated with public safety hazards, e.g., motor vehicle accidents. ${ }^{13}$ Therefore, if reasonable suspicion of posttraumatic SWD occurs, patients with TBI should preferably be examined with objective sleep laboratory examinations rather than self-reported sleep measures, because absence of subjective SWD does not rule out clinically significant posttraumatic sleep and wake problems. Consequently, evidence from this study and previous observations could be incorporated into future guidelines regarding the management of patients with TBI.

We found a strong correlation between TBI severity and pleiosomnia 6 months after TBI occurrence, suggesting that increased sleep need may function as an endogenous repair mechanism after TBI. ${ }^{1}$ One year later, this association between TBI severity and pleiosomnia disappeared. Of note, significant diffuse axonal injury may be induced by a wide range of TBI severities (including mild TBI). ${ }^{14,15}$ In this line, we hypothesize that any type of TBI could induce damage to highly vulnerable sleep-relevant cerebral centers. ${ }^{16,17}$ However, we cannot rule out that other factors contribute to chronic posttraumatic pleiosomnia, and further studies are needed to improve our understanding of the pathophysiologic mechanisms underlying posttraumatic SWD to facilitate research on novel therapeutic options.

\section{AUTHOR CONTRIBUTIONS}

L.L. Imbach: study concept, acquisition and analysis of data, writing of the manuscript. F. Büchele: study concept, acquisition and analysis of data, writing of the manuscript. P.O. Valko: acquisition and analysis of data, review of the manuscript. T. Li: acquisition and analysis of data. A. Maric: acquisition and analysis of data. J.F. Stover: acquisition and analysis of data. C.L. Bassetti: study concept. L. Mica: acquisition and analysis of data. E. Werth: acquisition and analysis of data, writing of the manuscript. C.R. Baumann: study concept, acquisition and analysis of data, writing of the manuscript.

\section{ACKNOWLEDGMENT}

The authors thank Dr. Dilek Könü and Dr. Oguzkan Sürücü for their help in patient recruitment.

\section{STUDY FUNDING}

This study was supported by the Swiss National Science Foundation (SNF 125504) and the Clinical Research Priority Program Sleep and Health of the University of Zurich.

\section{DISCLOSURE}

The authors report no disclosures relevant to the manuscript. Go to Neurology.org for full disclosures.

Received September 22, 2015. Accepted in final form February 1, 2016.

\section{REFERENCES}

1. Imbach LL, Valko PO, Li T, et al. Increased sleep need and daytime sleepiness 6 months after traumatic brain injury: a prospective controlled clinical trial. Brain 2015; 138:726-735.

2. Baumann CR, Werth E, Stocker R, Ludwig $S$, Bassetti CL. Sleep-wake disturbances 6 months after traumatic brain injury: a prospective study. Brain 2007;130: 1873-1883.

3. Castriotta RJ, Wilde MC, Lai JM, Atanasov S, Masel BE, Kuna ST. Prevalence and consequences of sleep disorders in traumatic brain injury. J Clin Sleep Med 2007;3: 349-356.

4. Kempf J, Werth E, Kaiser PR, Bassetti CL, Baumann CR. Sleep-wake disturbances 3 years after traumatic brain injury. J Neurol Neurosurg Psychiatr 2010;81:1402-1405.

5. Sommerauer M, Valko PO, Werth E, Baumann CR. Excessive sleep need following traumatic brain injury: a case-control study of 36 patients. J Sleep Res 2013;22: 634-639.

6. Ouellet MC, Savard J, Morin CM. Insomnia following traumatic brain injury: a review. Neurorehabil Neural Repair 2004;18:187-198.

7. Roozenbeek B, Maas AI, Menon DK. Changing patterns in the epidemiology of traumatic brain injury. Nat Rev Neurol 2013;9:231-236. 
8. Ouellet MC, Beaulieu-Bonneau S, Morin CM. Sleepwake disturbances after traumatic brain injury. Lancet Neurol 2015;14:746-757.

9. Cippà MA, Baumann CR, Siccoli MM, Bassetti CL, Poryazova R, Werth E. Actigraphic assessment of periodic leg movements in patients with restless legs syndrome. J Sleep Res 2013;22:589-592.

10. American Academy of Sleep Medicine. International Classification of Sleep Disorders (ICSD-2), Diagnostic and Coding Manual, 2nd ed. Westchester, IL: American Academy of Sleep Disorders Association; 2005.

11. Goldstein M. Traumatic brain injury: a silent epidemic. Ann Neurol 1990;27:327.

12. Ouellet MC, Morin CM. Subjective and objective measures of insomnia in the context of traumatic brain injury: a preliminary study. Sleep Med 2006;7: 486-497.
13. Drake C, Roehrs T, Breslau N, et al. The 10-year risk of verified motor vehicle crashes in relation to physiologic sleepiness. Sleep 2010;33:745-752.

14. Johnson VE, Stewart W, Smith DH. Axonal pathology in traumatic brain injury. Exp Neurol 2013;246:35-43.

15. Blumbergs PC, Scott G, Vis JM, Wainwright H, Simpson DA, McLean AJ. Topography of axonal injury as defined by amyloid precursor protein and the sector scoring method in mild and severe closed head injury. J Neurotrauma 1995;12:565-572.

16. Valko PO, Gavrilov YV, Yamamoto M, et al. Damage to histaminergic tuberomammillary neurons and other hypothalamic neurons with traumatic brain injury. Ann Neurol 2015;77:177-182.

17. Baumann CR, Bassetti CL, Valko PO, et al. Loss of hypocretin (orexin) neurons with traumatic brain injury. Ann Neurol 2009;66:555-559.

\section{AAN Practice Management Webinars: The FASTEST Way to Improve Your Practice}

Timely. Affordable. Convenient. In just one hour, you can learn the information on topics that affect the success of your practice, from coding and reimbursement to working with new technologies and health system changes. AAN members pay only $\$ 99$ per live or recorded session—or get all 10 webinars for only \$189-and you can earn CME credit! Visit AAN.com/view/pmw16 to register for these webinars:

- May 11: Merit, Incentives, Use, and Quality: The Alphabet Soup of Value-based Care

- June 14: Get Better at Getting Better: A Neurology Guide to Quality Improvement

\section{Discover Altmetrics}

See real-time downloads and online activity for articles!

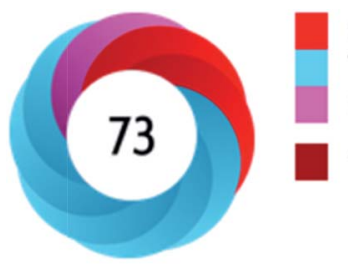

Picked up by 8 news outlets

Tweeted by 18

Mentioned in 1 Google+ posts

12 readers on Mendeley

\section{See more details}

Authors and readers alike can view real-time data on articles including downloads and online activity across multiple sources. Click on the "Article Metrics" link in the right column of an article for details. To learn more about article metrics visit http://www.neurology.org/site/misc/article_usage.xhtml. 


\section{Neurology}

\section{Sleep-wake disorders persist 18 months after traumatic brain injury but remain underrecognized}

Lukas L. Imbach, Fabian Büchele, Philipp O. Valko, et al.

Neurology 2016;86;1945-1949 Published Online before print April 27, 2016

DOI 10.1212/WNL.0000000000002697

This information is current as of April 27, 2016

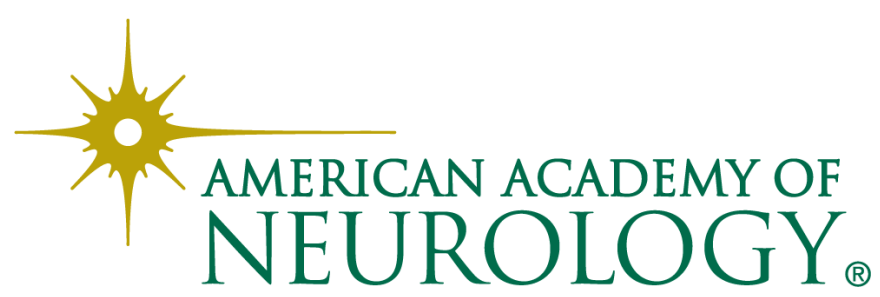




\section{Updated Information \& Services}

\section{Supplementary Material}

\section{References}

Citations

Subspecialty Collections

Permissions \& Licensing

Reprints including high resolution figures, can be found at:

http://www.neurology.org/content/86/21/1945.full.html

Supplementary material can be found at:

http://www.neurology.org/content/suppl/2016/04/28/WNL.0000000000 002697.DC1.html

http://www.neurology.org/content/suppl/2016/06/30/WNL.0000000000 002697.DC2.html

This article cites 16 articles, 4 of which you can access for free at: http://www.neurology.org/content/86/21/1945.full.html\#\#ref-list-1

This article has been cited by 1 HighWire-hosted articles: http://www.neurology.org/content/86/21/1945.full.html\#\#otherarticles

This article, along with others on similar topics, appears in the following collection(s):

\section{Brain trauma}

http://www.neurology.org//cgi/collection/brain_trauma

Clinical trials Observational study (Cohort, Case control)

http://www.neurology.org//cgi/collection/clinical_trials_observational_ study_cohort_case_control

\section{Cohort studies}

http://www.neurology.org//cgi/collection/cohort_studies

Other hypersomnias

http://www.neurology.org//cgi/collection/other_hypersomnias

Prognosis

http://www.neurology.org//cgi/collection/prognosis

Information about reproducing this article in parts (figures,tables) or in its entirety can be found online at:

http://www.neurology.org/misc/about.xhtml\#permissions

Information about ordering reprints can be found online: http://www.neurology.org/misc/addir.xhtml\#reprintsus

Neurology ${ }^{\circledR}$ is the official journal of the American Academy of Neurology. Published continuously since 1951, it is now a weekly with 48 issues per year. Copyright @ 2016 American Academy of Neurology. All rights reserved. Print ISSN: 0028-3878. Online ISSN: 1526-632X.

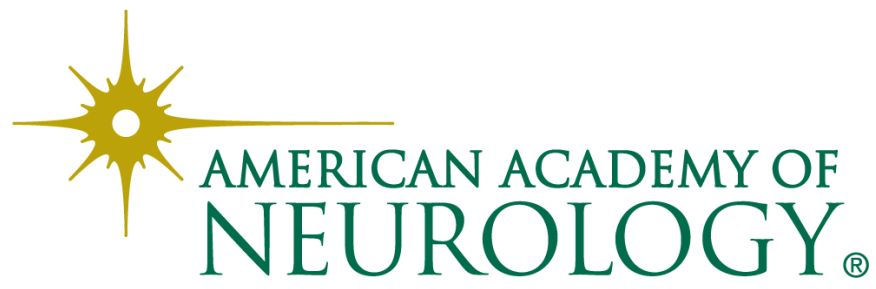

